\title{
Estética de la fotografía publicitaria
}

\author{
Aesthetics of advertising photography \\ Cristina $\mathrm{M}^{\mathrm{a}}$ SánchezTorreblanca \\ ${ }^{1}$ Historiadora del Arte por la Universidad de Málaga, España (cstorreblanca@gmail.com)
}

Recibido el 10 de abril de 2017; revisado el 15 de abril de 2017; aceptado el 9 de juniode 2017; publicado el 01 de julio de 2017

RESUMEN: La cultura contemporánea es eminentemente visual, y en ella, la publicidad juega un importante papel. Buscando comunicar y persuadir al espectador, estas imágenes se adaptan a una serie de estereotipos sociales y culturales en los que resulta imprescindible el carácter estético. En este trabajo se analizarán los anuncios realizados en el siglo XXI a través del medio fotográfico, con el fin de establecer su identificación en relación a las categorías estéticas de lo bello, lo sublime, lo trágico, lo feo, lo cómico y lo kitsch.

PALABRAS CLAVE: Cultura visual, estética, fotografía publicitaria, anuncio.

\begin{abstract}
The contemporary culture, where advertising plays an important role, is eminently visual. With the final purpose of informing and pesrsuading to the costumer, these images are adaptes to a series of social and cultural stereotypes. The subjetct of this assignment is to analyze the link between the advertisements created in the 21 st century and the aesthetic categories such as the beauty, the sublime, the tragic, the ugliness, the comedic and the kitsch.
\end{abstract}

KEYWORDS: Visual culture, aesthetic, advertising photography, advertisement. 
La imagen tiene el poder de informar y persuadir, sustituyendo, así, el empleo de la ilustración a través de su valor documental y originalidad (Eguizábal, 2001: 13), lo que la ha constituido como el medio idóneo para la publicidad. Su objetivo consiste en informar sobre un producto, con el fin de lograr el consumo 1, recurriendo especialmente a la dimensión estética mediante determinadas fórmulas y artificios; por ello, indagaremos en la relación de la estética con el ámbito fotográfico.

La unión entre estética y publicidad se genera, fundamentalmente, a finales del siglo XX a través de la publicidad tanto visual como audiovisual (Zapata, 2013: 11). Estas imágenes se identificarán con las distintas categorías estéticas, introduciendo diversos cambios frente al ámbito pictórico debido a la evolución de las técnicas fotográficas y digitales, aunque conservando siempre el poder de la persuasión publicitaria. Los encuentros entre fotografía y publicidad darán lugar a campañas protagonizadas por la belleza, lo sublime, lo trágico, lo feo, lo cómico y lo kitsch.

En primer lugar, destacaremos la belleza y los cánones establecidos en torno a ella en la actualidad, destacando la fotografía de moda. A continuación, se hablará de lo sublime en relación al paisaje, especialmente en los anuncios de automóviles y perfumes; además, nos centraremos en una nueva subcategoría que aparece propiciada por los avances digitales: lo sublime tecnológico. La siguiente categoría será lo trágico y su empleo en la mayoría de ocasiones para campañas de concienciación social. En el siguiente apartado se tratará la estrecha relación entre las categorías de lo feo y lo cómico. Por último, se tratará la estética de lo kitsch y el empleo de clichés en publicidad.

\section{La belleza}

Los ideales de belleza han generado conceptos estéticos que han definido gran parte de la historia de los estilos (Chaparro y Guerrero, 2009: 67-71). En el último siglo, es infinita la cantidad de fotografías publicitarias que encontramos, proporcionándonos e imponiéndonos el concepto de belleza idealizada; éste se ha visto acrecentado con el avance de la técnica fotográfica y los programas de edición fotográfica. La belleza es - en el sentido puramente estético (Tatarkiewicz, 2005: 350) - lo más importante en la historia de la publicidad, donde se ha tratado en la amplia mayoría de complacer los gustos sociales (Baudrillard, 2009: 105). Los mass media transmiten un concepto estético ligado con el buen físico y el éxito tanto profesional como social, que se transfieren desde el producto al consumidor (Walzer, 2014: 153) a través de la compra.

\footnotetext{
${ }^{1}$ A pesar de no presentar siempre la verdad, es el medio que transmite mayor sensación de veracidad.
} 
Es destacable la recuperación de la idea clásica sobre la figura del atleta como héroe y su posición de poder, conformada en nuestra época a través de las celebrities ya sean modelos de pasarela, deportistas 2 y algunos actores). A través de la obtención del producto, el espectador medio logrará similar su identidad. Sin embargo, esta belleza estética es independiente de la moral; ya que en nuestra sociedad la dimensión física es más conveniente que la dimensión mental.

\section{Lo sublime}

La relación entre hombre y naturaleza en el arte ha sido reflejada en la publicidad desde finales del siglo XIX (Pérez, 2000: 29). La naturaleza aparece como algo desconocido que pone a prueba la capacidad del hombre. Como ya veíamos en las obras de Caspar David Friedrich, el hombre se enfrenta a fuerzas terribles incapaces de controlar. Por ello, aparece el cásico personaje romántico: el aventurero capaz de enfrentar esa naturaleza salvaje a lo desconocido. Esta presencia del hombre en el paisaje sublime destaca especialmente en los anuncios de perfumes y automóviles.

Las campañas publicitarias son experiencias especialmente basadas en el éxito y la conquista. El objetivo que el público desea alcanzar es el de ser hombres y mujeres de éxito; motivo por el cual aparece el concepto de lo sublime mediático, donde los personajes famosos se muestran como ideal a alcanzar. Por lo tanto, el sentimiento de lo sublime natural ha sido alterado y adaptado a los medios tecnológicos y gustos actuales.

Desde mediados del siglo XX, el público asocia el sentimiento de lo sublime a escenarios más inmediatos y cotidianos como son la moda, el cuerpo, la publicidad, etc (Fajardo, 2009: 30). Puede resultar contradictoria la aplicación de lo sublime - cuyo fundamento no se basa en el objeto si no en la genialidad de su creador - a la publicidad y su finalidad de consumo material, sus facultades y especialmente las consecuencias de la compra.

A pesar de este progreso técnico, la presencia del paisaje no podía desaparecer de la fotografía, ya que éste fue uno de los temas principales en el inicio de su historia. En el paisaje, la mirada se da hacia el interior, hacia el inconsciente (Arguillol, 2006: 68); la contemplación de la naturaleza y lo 
exterior es secundario. Según Rafael Argullol, una montaña o un huracán no reflejan sucesos geográficos o climatológicos, sino "estados de la subjetividad” (Arguillol, 2006: 68).

\section{Lo sublime tecnológico}

Las categorías estéticas mantienen hoy intactos muchos de sus atributos originales. No obstante, se han producido ligeros cambios debidos al importante papel que juega la tecnología, hasta el punto de alterar la relación del ser humano con la naturaleza. La superación de lo sensible en la publicidad de lo sublime se logra a través de la mediación de la tecnología, la cual nos permite dominar lo natural. Se introduce así la categoría de lo sublime tecnológico (Fernández, 2007: 228).

Esta nueva derivación proviene de la posmodernidad 3 y el lugar destacado que ocupa el sentimiento de lo sublime (Murcia, 2009: 228). Según el filósofo Frederic Jameson, la relación burkeana y kantiana entre lo sublime y la naturaleza ya no es posible, pues el avance tecnológico impide su desmesura (Jameson, 1996: 9). Lo sublime surge ahora de un lugar diferente que nos produce terror: la tecnología. Por lo tanto, en la posmodernidad, lo sublime tecnológico se manifiesta por la inconmensurabilidad de los espacios relacionados con el mundo digital. Se representa, así, un nuevo tipo de exceso, inmenso y poderoso, que nos hace sentir atraídos (Borges, 2008: 75), donde encontramos los nuevos paisajes de nuestra época con sus imponentes arquitecturas futuristas.

Hoy en día nos servimos de herramientas digitales, entre las que se encuentran, esencialmente, el teléfono móvil e internet y, al igual que antes nos parecían incomprensibles las fuerzas de la naturaleza dignificadas en la representación, estos objetos se presentan de la misma manera. A través de ellos obtenemos todas las respuestas posibles a esas situaciones adversas que se nos plantean frente a la naturaleza de una forma inmediata y eficaz, en cualquier lugar y gracias a la capacidad de conexión que tienen.

\section{Lo trágico}

Los mensajes publicitarios habitualmente muestran una vida glorificada, creando momentos que el espectador aspira a simular. Es necesario que éste encuentre imágenes amables y evasivas que inciten al consumo. En cambio, en las obras que muestran una situación trágica, se manifiesta una situación terrible, funesta y conflictiva. Podemos ver que pocas marcas se atreven a adoptar este tipo de estética 
menos complaciente, pues se arriesgan a provocar rechazo en el espectador. Una excepción serán las campañas de la marca italiana Benetton, por Oliviero Toscani, durante los años noventa.

Esta actitud trágica suele tener como fin un enfoque activista y reivindicativo, que busca intencionadamente incomodar al espectador. Éstas llegan a ser censuradas y prohibidas por la dureza de sus imágenes, en las cuales suelen aparecer temas relacionados con la denuncia social o las campañas benéficas, solidarias, medioambientales, etc., haciendo uso del horror y del impacto. Se puede destacar la presencia de enfermedades tales como el SIDA o la anorexia.

\section{Lo feo}

Son numerosas las definiciones proporcionadas acerca de la belleza, sin embargo, no ha ocurrido lo mismo con lo feo, siempre definido como la oposición a lo bello. Se identifica así con una reacción de disgusto, considerado como horrendo, desagradable, obsceno, etc. En estas campañas protagonizadas por lo feo, encontramos situaciones contrarias a la visión idílica, incluyendo una intención cómica en la mayoría de los casos a través de la exageración de rasgos. Así, se muestran personas cuyo aspecto físico no corresponde al canon de belleza aceptado en los anuncios de moda.

\section{Lo cómico}

La experiencia publicitaria ofrece, a través de lo cómico, una nueva perspectiva de la realidad más positiva (García, 2004: 217), adaptando el mensaje al comportamiento de los grupos sociales en la vida cotidiana; Mediante el uso de estereotipos, la creatividad y el humor se convierten en técnicas de persuasión. Con ello, no sólo se logra perpetuar la marca en la memoria del espectador, sino identificarla con una sensación agradable.

El empleo de esta categoría se dará en productos lúdicos o poco atractivos en los que es difícil resaltar valores de éxito con los que el espectador quiere identificarse4. Destaca el empleo de la caricatura, la iconografía popular y las personificaciones.

\footnotetext{
${ }^{4}$ Será necesario un lenguaje claro y de fácil comprensión para la mayoría de espectadores. Podemos identificar esta característica con "lo cómico significativo" establecido por Charles Baudelaire. Véase BAUDELAIRE, Charles (1973), "De la esencia de la risa y en general de lo cómico en las artes plásticas", en Lo cómico y la caricatura. Grijalbo, Barcelona.
} 


\section{Lo kitsch}

El objeto kitsch imita las fórmulas hasta convertirlas en clichés, apropiándose de los elementos propios del contexto original para alterar la intención inicial del mensaje (Broch, 1973: 9-13). Consiste en la búsqueda del confort, la mediocridad, la acumulación y, al igual que la publicidad, el consumo. Esto justifica el empleo de elementos reconocibles de la cultura popular en anuncios, para así lograr una fácil identificación del espectador con el producto. Es este libre acceso lo que determina su éxito, ya que el público de masas busca la superficialidad y vaga belleza, justificando así el empleo de elementos reconocibles de la cultura popular o ciertas iconografías de la historia del Arte, como la mitológica.

\section{Conclusiones}

Tras describir brevemente las categorías estéticas, podemos llegar a la conclusión del importante papel que ocupa la cuestión estética en los medios publicitarios, en relación a las circunstancias sociales y culturales. Hemos podido observar la importancia de la belleza a través de figuras mediáticas, que en el caso de los anuncios relacionados con la belleza y lo sublime, llegan a eclipsar al propio producto. Esto se debe a la transformación producida en la publicidad desde la posmodernidad, en la que los medios tratan de persuadir al espectador a través de la puesta en valor de experiencias y sensaciones, donde el ser humano está por encima del objeto de consumo. Estas experiencias suceden en paisajes espectaculares, como hemos visto especialmente en las campañas publicitarias de automóviles, con esta intención de evasión de la cotidianidad.

Este rechazo a la realidad se contrapone a las campañas de concienciación social, se nos muestran fragmentos de la realidad menos amable, de ahí que la categoría de lo trágico sea aplicada en pocas ocasiones a los anuncios de productos. Como oposición, hemos encontrado una estrecha relación entre las categorías de lo feo y lo cómico, mediante la puesta en evidencia de los aspectos más cotidianos.

Finalmente, podemos observar cómo la estética más cuidada está presente en los anuncios dedicados al cuidado personal, ya sean perfumes, moda, o el automóvil como forma de prestigio. Es en este tipo de anuncios donde podemos observar mayor relación entre la fotografía publicitaria y su elaboración a partir de las pautas de la fotografía artística o de la propia pintura. 
Mediante la puesta en escena, las técnicas digitales y la creatividad artística se produce una fotografía que parte de la realidad para inventar un mundo idílico que actúe como señuelo. Para ello, es necesario la aplicación de criterios estéticos, tanto en las campañas publicitarias como en la propia confección de los productos anunciados.

Los anuncios impresos cada vez son más visuales y contienen menos información, ya que el objetivo de la publicidad es atraer a través de la mirada; como señala Roland Barthes, la fotografía publicitaria refuerza el significado de sus imágenes con la mayor claridad y énfasis posible (Barthes, 1993: 239). Con ello, la principal intención es la de crear una relación entre el espectador y la marca, no sólo se trata del acto de la compra en un momento concreto, sino de crear una fidelidad con perspectivas futuras (Eguizábal, 2012: 122).

En definitiva, podríamos considerar la fotografía publicitaria como un "arte aplicado, al servicio de unos objetivos comerciales". Al fin y al cabo, son puestas en escena donde cada ínfimo detalle está calculado. A través de la estética se evidencian estos valores comerciales. Sin embargo, su principal finalidad comercial le impide convertirse en arte, ya que a pesar de su evolución estética, prevalece el valor comercial por encima del producto, por lo que el anuncio no existiría sin otro motivo que el consumo (Walzer, 2010: 296-306). 


\section{Referencias bibliográficas}

ARGULLOL, Rafael (2006). La atracción del abismo. Un itinerario por el paisaje romántico. Quaderns Crema: Barcelona.

BALADO ALBIOL, Consuelo y BREVA FRANCH, Eva (2005). “'Se merece la publicidad un museo? Estudio y análisis mundial de los museos de publicidad”, Comunicación Vivat Academia, nº9, pp. 1-19.

BARTHES, Roland (1993). La aventura semiológica. Ediciones Paidós Ibérica: Barcelona.

BAUDELAIRE, Charles (1973). Lo cómico y la caricatura. Editorial Grijalbo: Barcelona.

BAUDRILLARD, Jean (2009). La sociedad de consumo. Sus mitos, sus estructuras. Editorial Siglo XXI: Madrid.

BORGES HOLANDA, Giodana (2008). Do sublime tecnológico às cartografías dos fluxos.

Pontificia Universidade Católica do Rio de Janeiro: Río de Janeiro.

BROCH, Hermann (1973). Kitsch, vanguardia y el arte por el arte. Editorial Lumen: Barcelona.

BURKE, Edmund (2014). Indagación filosófica sobre el origen de nuestras ideas acerca de lo sublime y de lo bello. Alianza Editorial: Madrid.

CENTOCCHI, Claudio (2007), "Una aproximación a la publicidad cómplice actual: cuando las celebrities dejan de alabar", Pensar la publicidad, n 1, pp. 219-234.

CENTOCCHI, Claudio (2009), "Semblantes de la publicidad postmoderna", Pensar la publicidad, $\mathrm{n}^{\mathrm{o}} 3$, pp. 15-30.

CHAPARRO, Élver, y GUERRERO NIETO, Yulieth (2013), “Cultura y estética popular: Lo híbrido, el gusto y la experiencia", Calle 14, no $10, \mathrm{pp} .68-71$.

CHEVRIER, Jean-François (2007). La fotografía entre las bellas artes y los medios de comunicación. Editorial Gustavo Gili: Barcelona.

COSTA, Mario (2005). 7th Generative Art Conference Proceeding. Politecnico di Milano: Milán.

DORFLES, Gillo (1968). El kitsch. Antología del mal gusto. Editorial Lumen: Barcelona.

ECO, Umberto (2007). Historia de la fealdad. Editorial Lumen: Barcelona.

ECO, Umberto (1994). La estructura ausente. Introducción a la semiótica. Editorial Lumen:

Barcelona.

EGUIZÁBAL, Raúl (2001). Fotografía publicitaria. Ediciones Cátedra: Madrid.

EGUIZÁBAL, Raúl (2012), "Neomitologías: la estrategia del mito”, Redmarka, no 9, pp. 91-129. 
ESTEBAN ORTEGA, Joaquín (2009). Cultura contemporánea y pensamiento trágico. Universidad Europea Miguel de Cervantes: Valladolid.

FAJARDO FAJARDO, Carlos (2009), "El arte en el umbral. Estética y cultura de mercado", Cuadernos de lingüística hispánica, nº 4, pp. 23-34.

FAJARDO FAJARDO, Carlos (2001). Estética y posmodernidad. Nuevos contextos y sensibilidades. Ediciones Abya-Yala: Quito.

FANDOS, Manuel y MARTÍNEZ, María José (1997), “Ética y estética de la imagen”, Comunicar, $\mathrm{n}^{\circ} 9$, pp. 37-42.

FERNÁNDEZ GUERRERO, Olga (2007), "Estética y publicidad: elementos clásicos en la fotografía actual”, Quintas jornadas: II. Imagen y tecnología, pp. 217-228.

GARCÍA BANDERA, Noelia (2000), "Iconografía femenina y publicidad de perfumes”, Boletín de arte, $\mathrm{n}^{\circ} 21$, pp. 365-394.

GARCÍA BANDERA, Noelia (2004). La Esencia de la Belleza: análisis iconográfico de la mujer en la publicidad de perfumes (1990-2004). Tesis Universidad de Málaga, dirigida por María Teresa Méndez Baiges: Málaga.

GARCÍA BANDERA, Noelia (2007), “Naked or nude?”, Boletín de arte, nº 28, pp. 507-522.

HERNÁNDEZ MUÑOZ, Silvia María (2008). El humor como estrategia y reflexión en la publicidad española (2007 y 2009). Tesis de la Universitat Politècnica de València, dirigida por Vicente Ponce Ferrer: Valencia.

HUYSSEN, Andreas (1988). Modernidad y postmodernidad. Alianza Editorial: Madrid.

JAMESON, Fredric (1996). Teoría de la postmodernidad. Editorial Trotta: Madrid.

KANT, Immanuel (1991). Crítica del juicio. Editorial Espasa-Calpe: Madrid.

MADRIZ FLORES, Kathy (2013), "Las dos caras del kitsch: el arte de mentir o mentira artística", Lenguas modernas, $\mathrm{n}^{\mathrm{o}} 18$, pp. 399-410.

MARTÍNEZ RODRIGO, Estrella, y RAYA GONZÁLEZ, Pura (2004). Comunicación e interactividad. ACCI: Madrid.

MANDOKI, Katya (2007). Estética cotidiana y juegos de la cultura: Prosaica Uno. Editorial Siglo XXI: Madrid.

MURCIA SERRANO, Inmaculada (2009), "Lo sublime de Edmund Burke y la estetización postmoderna de la tecnología”, Revista de Estética y Teoría de las Artes, no 8, pp. 17-38.

PÉREZ GAULI, Juan Carlos (2000). El cuerpo en venta. Relación entre arte y publicidad. Editorial Cátedra: Madrid. 
RAMÍREZ, Juan Antonio (1988). Medios de masas e historia del arte. Cuadernos Arte Cátedra: Madrid.

REY FUENTES, Juan (1994), "El hombre bello: un nuevo modelo para un nuevo consumidor", Revista Universitaria de Publicidad y Relaciones Públicas, nº 1, pp. 151-162.

RIBALTA, Jorge (2004). Efecto real. Debates posmodernos sobre fotografía. Editorial Gustavo Gili: Barcelona.

RÍOS MOYANO, Sonia (2013), "Imágenes de consumo para un mundo global: héroes y villanos en clave artística", en MÍNGUEZ CORNELLES, Víctor, (coord.), Las artes y la arquitectura del poder. España, Universitat Jaume I, pp. 2453-2466.

TATARKIEWICZ, Wladyslaw (1992). Historia de seis ideas. Editorial Tecnos: Madrid.

VÁSQUEZ ROCA, Adolfo (2005), "La crisis de las vanguardias artísticas y el debate modernidad postmodernidad", Arte, Individuo y Sociedad, n 17, pp. 133-154.

VILASUSO, Rolando (2013). La publicidad audiovisual: una forma de arte posmoderno. Editorial Lamm: México.

WALZER, Alejandra (2010), “Arte y publicidad. Elementos para debate”, Aisthesis, no 47, pp. 296306.

WALZER, Alejandra (2014). La belleza: de la metafísica al spot. Ediciones Octaedro: Barcelona.

ZAPATA WHITE, Mario Alberto (2013). Las estrategias estéticas en la publicidad: un recorrido por los juegos de la persuasión. Universidad Nacional de Colombia: Colombia.

http://adsoftheworld.com/ (Consulta: 28/05/2016)

https://www.coloribus.com/ (Consulta: 28/05/2016)

http://www.marketingdirecto.com/punto-de-vista/la-columna/el-humor-como-parte-integral-de-lapublicidad-1/ (Consulta: 27/05/2016)

https://www.pinterest.com/ (Consulta: 28/05/2016) 